\title{
Clonagem de embriões bovinos a partir de células somáticas
}

\section{Clonación de embriones bovinos a partir de células somáticas}

\section{Cloning bovine embryos from somatic cells}

\section{Edgar M. Mogollón-Waltero', Marco R. Bourg-de Mello², Angelo J. Burla-Días ${ }^{3}$}

MV, MSc, PhD, Grupo de investigación en nutrición, toxicología y reproducción animal (GRUPONTRA), facultad de Medicina Veterinariay Zootecnia, Universidad Cooperativa de Colombia sede Bucaramanga

MV, Msc, PhD, Professor Adjunto Universidade Federal Rural do Rio de Janeiro (UFRRJ)

MV, MSc, PhD, Laboratório de reprodução e melhoramento genético animal LRMGA, Centro de Ciência e Tecnologia Agropecuária CCTA, Universidade estadual do norte fluminense Darcy Ribeiro UENF

Email: mao5_2000@yahoo.com

Recibido: Agosto 13 de 2013. Aceptado: Diciembre 2 de 2013.

\section{Resumo}

No presente artigo revisa-se dedicadamente a literatura do tema da clonagem tentando levar o leitor paulatinamente através dos avanços da técnica até alcançar as mais novas alternativas propostas pelos cientistas, e incluindo os erros mais comumente acontecidos nelas. A finalidade é mostrar o amplio panorama que tem aberto esta biotecnologia para a humanidade toda.

Palabras chave: Transferência nuclear, fissão, paraclonagem, clonagem verdadeira, genoma mitocondrial.

\section{Resumen}

En el presente artículo se revisa detenidamente la literatura en el tema de clonación, intentando llevar al lector paulatinamente a través de los avances de la técnica hasta alcanzar las más nuevas alternativas propuestas por los investigadores, incluyendo los errores más comúnmente cometidos. La finalidad es mostrar el amplio panorama que a abierto esta biotecnología para la humanidad.

Palabras Clave: Transferência nuclear, fissão, paraclonagem, clonagem verdadeira, genoma mitocondrial.

\begin{abstract}
Abstratc
The present article provides a review of the pertinent literature on the topic of cloning. It aims to take the reader gradually through the advances made so far regarding the technique, to the newest alternatives proposed by researchers, including the most commonly committed errors, to unveil the broad panorama this biotechnology has opened up for humankind.
\end{abstract}

Key words: Nuclear transfer, fission, paraclone colony, true cloning, mitochondrial genome. 


\section{Introdução}

Por definição clone é uma população de moléculas, células ou organismos que se originaram de uma única molécula ou célula e que, por tanto, são idênticas a célula original e entre elas. Na espécie humana os gêmeos idênticos são exemplo de clones naturais originados pela divisão de um óvulo após fertilização. (Baguisi et al., 1999).

A clonagem de embriões bovinos utilizando células somáticas apresenta-se na atualidade como a única biotecnologia reprodutiva capaz de garantir que o individuo resultante irá conservar $100 \%$ dos genes do seu progenitor, visto que nesse tipo de reprodução não acontece o "crossing over", o que faz dela a ferramenta perfeita para replicar animais transgênicos previamente "desenhados"; por exemplo, para a produção de uma determinada proteína recombinante de utilidade na saúde humana.

Esta técnica pode ser usada na conservação e regeneração dos recursos genéticos e contribui para um maior entendimento a respeito da interação núcleo-citoplasma e na reprogramação nuclear (Pereira e Freitas, 2009).

Na clonagem por transferência de núcleo (TN) é realizada a fusão de uma célula (doadora de núcleo) com um oócito previamente enucleado. A célula resultante dessa união é capaz de converter-se em um embrião com habilidade para se desenvolver e gerar um novo indivíduo.

A TN de células somáticas envolve procedimentos que podem afetar a viabilidade embrionária e fetal. Tem sido reportado que só 1 a $10 \%$ dos embriões transferidos desenvolvem à termo (Tamada e Kikyo 2004; Wells, 2005). Dentre os fatores envolvidos pode-se assinalar o tempo entre a fusão e a ativação induzida (Akagi et al., 2003, Martínez Diaz et al., 2003); a linhagem celular utilizada como doadora de núcleo (Tian et al., 2003); a coordenação do ciclo celular entre célula doadora e o oócito receptor (Campbell et al., 1996); e o processo de transferência nuclear por fusão ou micro microinjeção (Kurome et al., 2003).

Desta maneira na presente revisão serão abordados alguns aspectos relevantes relacionados à técnica de clonagem por transferência nuclear, enfatizando os problemas mais comuns e os avanços obtidos nos últimos anos.

\section{Revisão de literatura}

\section{Breve histórico da transferência nuclear}

O primeiro transplante de núcleos foi realizado a partir de células embrionárias de Rã pipiens irradiadas com luz ultravioleta (UV). Este experimento eliminou o núcleo haplóide de um oócito não fecundado, substituindo por um núcleo diplóide procedente de uma célula somática; tornando possível o início do desenvolvimento embrionário. Foram necessários 197 embriões reconstituídos para conseguir que 27 tivessem o desenvolvimento embrionário, originando então 27 girinos clonados (Briggs e King, 1952).

Estes pesquisadores comprovaram que a clonagem por transferência de núcleos de blastômeros no estágio de blástula permitia o desenvolvimento embrionário, mas se esse procedimento fosse realizado com núcleos procedentes de células em estádio mais avançado de desenvolvimento os resultados de desenvolvimento diminuíam consideravelmente, concluindo então que as células diferenciadas não seriam totipotentes, o que limitaria sua capacidade para gerar um novo ser (Briggs e King, 1952).

O seguinte questionamento dos pesquisadores foi saber se os problemas observados no desenvolvimento embrionário dos clones eram causados pelo tipo de célula doadora do núcleo. Acreditava-se que se o núcleo implicado na clonagem fosse procedente do endoderma, de onde se formaria o intestino, por exemplo, o embrião poderia então carecer de estrutura não endodérmicas, como músculos, nervos, etc. podendo ser esse o motivo da baixa taxa de sucesso da técnica (Briggs e King, 1952).

Nos anos 60, foram realizados experimentos com o sapo africano com garras Xenopus laveis, conseguindo obter descendência adulta por clonagem de células de intestino de girino. Tal experimento demonstrou que uma célula pode diferenciar-se durante o desenvolvimento embrionário e posteriormente recuperar sua totipotência (Gurdon, 1962).

Gurdon (1965) usou a transferência nuclear com células das membranas das patas de rãs Rana pipiens adultas como doadoras de núcleos, mas os girinos não sobreviveram. Todos esses experimentos tinham a finalidade de demonstrar que as células já diferenciadas poderiam voltar a ser totipotentes e gerar um novo ser. Por tanto, uma vez que se esclareceu este fato, ficou definitivamente rejeitada a teoria da perda genética até então aceita.

A partir do descobrimento de Gurdon têm sido muitos os experimentos desenvolvidos e muitas as expectativas colocadas na técnica de transplante nuclear. Diversos trabalhos neste campo têm reforçado a teoria de que com a utilização de células embrionárias como doadoras de núcleos, poderiam se obter numerosos animais idênticos geneticamente (Saraiva et al., 2010; Recuerda, 2011). 
Este procedimento se conhece como "transplante nuclear em série" e consiste em transplantar um núcleo de um embrião para um oócito enucleado, assim ao obter um embrião precoce. Ele vai se converter no novo doador de outros núcleos que serão transferidos a outros oócitos enucleados, e como consequência, obter importantes quantidades de animais clonados, já que a técnica da clonagem é mais eficaz quando se transferem núcleos de células embrionárias que de células somáticas já diferenciadas (Recuerda, 2011).

Clonar anfíbios é um pouco mais simples que clonar mamíferos. Por exemplo, os óvulos da rã (Rana pipiens) são muito maiores que os de mamíferos, fato que facilita a manipulação para aplicação da técnica de transferência. Além disso, a reprodução dos anfíbios é externa, na água, enquanto que os mamíferos têm que gestar dentro do corpo, o novo ser.

O primeiro cientista que tentou clonar um mamífero (coelho - Oryctolagus cuniculus) foi Derek Bromhall, em 1975; porém todos os embriões morreram em fases iniciais do desenvolvimento. Para reativar a união do núcleo com o citoplasma, esse pesquisador utilizou o vírus Sendai e conseguiu a reativação, mas nenhum embrião sobreviveu (Bromhall, 1975).

Seis anos depois desse primeiro fracasso de Bromhall, em 1981, Illmense e Hope, pesquisadores da Universidade de Genebra na Suíça, anunciaram a clonagem de camundongos (Mus musculus).

Vários pesquisadores tentaram reproduzir as experiências de Illmensee, sem sucesso, repetindo o experimento várias vezes. Como os resultados continuaram sendo negativos, um periódico de grande impacto chegou a publicar que "a clonagem de animais por simples transplante nuclear é biologicamente impossível", fechando assim o destino da clonagem durante vinte anos (McGrath e Solter, 1984; Barañao, 2008).

Nos anos oitenta foram publicados vários estudos sobre clonagem de mamíferos. Willadsen (1986) obtive uma ovelha a partir de um embrião de oito células, enquanto Frist (1987), obteve um bezerro a partir de células de um embrião de vaca (Bos taurus). Com o passar do tempo continuaram a nascer animais clonados mediante transferência nuclear, mas sempre mediante uso de células embrionárias como doadoras de núcleo.

Em 1996 dois biólogos do Instituto Roslin (Escócia), empolgados com os resultados de Willadsen e o estudo da clonagem em mamíferos superiores, realizaram experimentos que culminaram com o nascimento de duas ovelhas clonadas, que foram chamadas de MEGAN e MORAG (Campbell, 1996).

Uma das grandes contribuições para o conhecimento científico nessa área realizada por Wilmut e Campbell foi à idéia de levar a célula embrionária ao estado de repouso ou G0, pela redução dos níveis energéticos dos meios de cultivo celular. Mesmo tratando-se de células embrionárias, depois de vários cultivos são obtidas células similares ás epiteliais (diferenciadas), segundo mostram os marcadores associados á diferenciação (Campbell et al., 1996; Wilmut et al, 1997).

Trabalhos posteriores deram como resultado a obtenção de animais clonados mediante a técnica de transferência nuclear sem levar o núcleo ao estado quiescente, de repouso ou G0, pelo que demonstrou que não é imprescindível que o núcleo esteja em dito estado para que se ative o desenvolvimento embrionário (Wakwyama et al., 1999).

Os estudos de Wilmut e Campbell continuaram apresentando resultados promissores, e em 5 de julho de 1996 nasceu na Escócia a ovelha clonada chamada DoIly, a partir de uma célula diferenciada. Dolly foi reproduzida por transferência nuclear a partir de uma célula somática diferenciada e não de células embrionárias de poucos dias de desenvolvimento. (Recuerda, 2011).

Esses estudos demonstraram que células somáticas que formam os tecidos de indivíduos adultos (especializadas), podem ser reprogramadas após sua fusão com um oócito enucleado, para iniciar o desenvolvimento embrionário dando origem a um animal com a mesma informação genética do animal doador da célula somática.

A clonagem reprodutiva permite obter cópias idênticas de indivíduos cujas características morfológicas e funcionais são conhecidas e só animais adultos podem aportar esses tipo de dados.

A célula somática que deu origem a Dolly foi uma célula epitelial da glândula mamária de uma ovelha da raça Finn Dorset, com 6 anos de idade, que estava no último terço de gestação, obtida por meio de biópsia. O oócito (citoplasto) foi oriundo de uma ovelha da raça Scottish Blackface de Cabeça Preta. As células somáticas foram cultivadas in vitro, e posteriormente conservadas durante cinco dias num meio pobre em soro fetal para levar o ciclo celular ao estado de repouso (De Miguel, 2008). Cada célula somática, foi introduzida em um oócito previamente enucleado. Estes oócitos estavam em metáfase II e tinham sido removidos cirurgicamente dos oviductos, após estimulação hormonal dos ovários. Então após a colocação 
da célula somática no espaço perivitelino foi realizada a fusão das membranas plasmáticas da célula doadora de núcleo e o citoplasto mediante estímulos elétricos (Wilmut et al., 1997).

Os estímulos elétricos permitiram reiniciar o processo de desenvolvimento embrionário e depois de 16 divisões no meio de cultivo os embriões foram transferidos para o útero da outra ovelha (Scottish Blackface); sendo que 148 dias depois nasceu Dolly, o primeiro mamífero obtido de uma célula somática de um animal adulto (Wilmut et al., 1997).

Dolly foi o resultado de um processo longo e complexo que precisou da reconstrução de pelo menos 277 embriões. Depois de seis dias de cultivo, foram recuperados 247 embriões e desses 29 atingiram a etapa de blastocisto e foram transferidos para 13 ovelhas da mesma raça sendo que apenas um chegou até o nascimento (Wilmut et al., 1997).

Em 1998, Dolly pariu uma fêmea chamada Bonie. A gestação e o parto foram normais, demonstrando assim que animais obtidos por transferência nuclear podem se reproduzir normalmente. Em 14 de fevereiro de 2003, aos seis anos de idade (a idade media da vida de uma ovelha é 11-12 anos), Dolly foi sacrificada no Instituto Roslin, devido a uma doença pulmonar progressiva, além disso sofria artrite e um processo de envelhecimento precoce. A necropsia mostrou que a patologia pulmonar se deveu a adenocarcinomas (câncer de origem viral comum em ovelhas).

As circunstancias da morte de Dolly reabriram o debate sobre a eficácia da transferência nuclear de células somáticas (SCNT), pelo que várias pesquisas centraram-se na busca de explicações para as possíveis causas de alterações na reprogramação epigenética (Wilmut, 2002).

\section{Métodos de clonagem}

\section{Partição de embriões pré-implantacionais (fissão)}

Este método não deve ser considerado como clonagem no sentido estrito, o mais correto seria denominar este procedimento de gemelação artificial, pela analogia com a gemelação natural. Os animais são geneticamente idênticos entre si, mas diferentes de seus progenitores (Gindoff, 1998).

\section{Paraclonagem}

A paraclonagem consiste na transferência de núcleos procedentes de blastômeros ou de células fetais, desen- volvidos em cultivos celulares, até óvulos não fecundados, previamente enucleados ou inclusos até zigotos enucleados. O "progenitor" dos animais clonados resultantes é um embrião ou feto. São equivalentes a gêmeos monozigóticos (Sims e First, 1994; Prathers, 1987).

\section{Clonagem verdadeira}

Consiste na transferência de núcleos de células de animais já nascidos, a oócitos enucleados, originando animais fenotipicamente quase idênticos entre si e muito parecidos com o doador do núcleo, só se diferenciam geneticamente por mutações somáticas e pelo genoma mitocondrial do oócito (Prathers, 1987).

\section{Clonagem por transferência nuclear}

\section{Seleção de células doadoras de núcleo}

As células somáticas adultas usualmente são mais difíceis de serem reprogramadas do que células fetais, o que se pode perceber pelas diferenças nas taxas de desenvolvimento in vivo obtidas com embriões oriundos de células destas diferentes origens. Pesquisadores avaliaram o desenvolvimento in vivo de embriões produzidos a partir de transferência nuclear de células embrionárias (NTEC), e células somáticas (NTSC) tanto de origem fetal, quanto de células somáticas adultas. Pesquisadores encontraram que as taxas de desenvolvimento in vivo foram menores para embriões produzidos a partir de células somáticas adultas do que para células fetais e embrionárias com sobrevivências pós-natais de $66,6 \%$ no grupo NTSC adulto e entre 80 e $83 \%$ nos outros grupos (Heyman et al., 2002).

Diversos tipos de tecido podem ser utilizados como doadores de núcleo, entre eles se conhecem as células epiteliais de glândula mamária, células do cumulus, células oviductais, células da granulosa, do fígado, do útero, músculo, linfócitos e fibroblastos, mas é difícil estabelecer se algum tipo pode ser melhor que outro, pois as metodologias de cultivo são também muito variadas. De modo geral, acredita-se que a eficiência da clonagem é inversamente proporcional ao estado de diferenciação da célula somática (Miyoshi et al., 2003; Campbell et al., 2007).

De outro modo o tempo de cultivo das células ou número de passagens antes da utilização para NT pode também afetar o sucesso da técnica. Foi reportado que longos períodos de cultivo (mais de 30 passagens) promovem maiores índices de apoptose nos embriões gerados, apesar de não comprometer as taxas de desenvolvimento embrionário até blastocisto (Jang et al., 2004). 
O procedimento para obtenção dos tecidos pode seguir um protocolo geral onde se obtém uma amostra de tecido, mediante biopsia em condiciones assépticas (no caso do animal vivo prefere-se a pele da orelha); esse tecido se conserva durante o transporte ao laboratório sob refrigeração, mantendo-o em tubos com meios com soro fetal bovino e sulfato de gentamicina (Martinez et al., 2007). No laboratório os tecidos são cortados em pedaços de aproximadamente $1 \mathrm{~mm}$, e estes são colocados em placas de Petri até sua aderência ao fundo e então são cobertos com meio de cultivo enriquecido com soro fetal. O cultivo é realizado em incubadoras a $39{ }^{\circ} \mathrm{C}$ e atmosfera de $5 \% \mathrm{CO}_{2}$, durante 7 a 14 dias. (Martinez et al., 2007; Martins et al., 2008).

Em anos anteriores foi avaliada a possibilidade de obtenção de células pluripotentes (células tronco) mediante o cultivo de células somáticas com estratos de células pluripotentes ou ainda, com fatores de reprogramação já isolados de células tronco e produzidas como proteínas recombinantes Oct4, Sox2, Klf4 e C-Myc). Estas tecnologias podem facilitar a reprogramação celular, com menor grau de injuria para as células doadoras de núcleo (Yamanaka, 2008).

\section{Seleção de oócitos receptores}

Os oócitos são obtidos por aspiração de ovários, provenientes de abatedouros ou de fêmeas selecionadas por aspiração folicular guiada por ultrasom. Os oócitos são maturados in vitro e selecionados quanto à extrusão do primeiro corpúsculo polar para a confirmação da maturação. (Bressan et al., 2008).

A fonte e a qualidade dos citoplastos representam um fator importante para o sucesso da técnica de transferência nuclear. Neste sentido, vários estudos já foram desenvolvidos buscando avaliar o estádio nuclear adequado deste citoplasto receptor em programas de transferência nuclear. Contudo, diferentes estudos têm demonstrado que oócitos em metáfase II (MII) são mais adequados para suportar a reprogramação nuclear São comparados aos demais estádios de maturação nuclear (Zou et al., 2001; Lee et al., 2007). Por esta razão, a maioria das pesquisas relata o uso de oócitos em MII maturados in vivo (Kato et al., 2000) ou in vitro (Zhou et al., 2007).

Os oócitos maturados in vitro têm sido muito utilizados, primeiro, porque geralmente se utilizam ovários oriundos de abatedouros, o que resulta em baixo custo e em significativa disponibilidade destas células; e segundo, porque possibilita um maior controle dos estádios da maturação (Pereira et al., 2009).

\section{Enucleação dos oócitos}

Para utilizar oócitos como citoplastos receptores na técnica de transferência nuclear, o material nuclear deve ser removido, resultando apenas no seu conteúdo citoplasmático. Em geral, este objetivo é atingido por aspiração da placa metafásica de oócitos em MII juntamente com o corpúsculo polar, usando micropipetas acopladas a micromanipuladores (Li et al., 2004).

Em muitas espécies, o conteúdo nuclear de oócitos em MII não é facilmente visível por microscopia óptica em virtude da presença de lipídeos citoplasmáticos. Por isso, antes do processo de enucleação, o oócito é marcado com Hoechst 33342, o qual apresenta uma fluorescência azul quando exposto à luz ultravioleta (Velilla et al., 2002).

Desta maneira, a remoção do material nuclear é confirmada pela ausência de fluorescência no oócito após a enucleação. Contudo tem sido demonstrado um efeito negativo da exposição do oócito à luz UV (Velilla et al., 2002), conseqüentemente tem sido recomendado não expor o citoplasma a esta radiação, mas sim apenas a porção removida presente na pipeta de aspiração (Chesné, 2006). Outra substância utilizada junto com o Hoechst 33342 é a citocalasina B cuja ação despolimeriza os microfilamentos e impede a citocinese (Sá et al., 2006).

Uma alternativa para a enucleação de oócitos em MII, a fim de se obter maior eficiência, é a remoção do material nuclear de oócitos ativados em telófase II. A aspiração mecânica de um pequeno volume de citoplasma adjacente à extrusão do segundo corpúsculo polar após a ativação é um método efetivo; não sendo necessária a visualização do DNA pela exposição à luz UV, uma vez que a cromatina ainda permanece justaposta ao segundo corpúsculo polar (Campbell et al., 2007).

Além do método de enucleação por aspiração mecânica, existe ainda o método químico, o qual consiste na remoção do material nuclear pelo uso de inibidores da topoisomerase (Hytell et al., 2001). Outra possibilidade é o uso da combinação do etanol e demecolcina (Ibáñez et al., 2003). Contudo, citoplastos preparados quimicamente resultam em menores taxas de clivagem e não produzem um bom desenvolvimento embrionário quando comparados aos métodos mecânicos de enucleação (Campbell et al., 2005).

\section{Transferência de núcleos}

Nesta etapa o núcleo da célula doadora (carioplasto) é transferido para o interior do citoplasma re- 
ceptor (citoplasto). Inicialmente a célula doadora é inserida no espaço perivitelino de um citoplasto para depois ser estimulado com um pulso elétrico, que vai promover a fusão das membranas adjacentes. O pulso elétrico induz assim a fusão da célula somática com o citoplasto formando um novo complexo, além de promover a liberação de cálcio intracelular, o que dá início ao processo de ativação (Heyman, 2005).

Em ruminantes, a reconstrução embrionária é geralmente alcançada por eletrofusão, mas esta etapa pode também ser obtida pelo uso de micropipetas por meio da injeção intracitoplasmática da célula intacta ou do núcleo isolado (Pereira et al, 2009).

\section{Ativação e cultivo embrionário}

Depois da fusão, os embriões reconstruídos são submetidos à ativação artificial, processo similar ao exercido pelo espermatozoide na fecundação. O evento característico da ativação oocitária é o início das oscilações intracelulares de cálcio, a exocitose de grânulos corticais, o recrutamento de mRNAs, a formação dos pró-núcleos e o início da síntese de DNA (Campbell et al., 2005).

Após a transferência de núcleo, a ploidia normal celular é mantida, aguardando a replicação do DNA. O citoplasto receptor que apresenta um alto nível de atividade do MPF promove o rompimento da membrana nuclear e a condensação prematura dos cromossomos. A ativação oocitária induz uma redução da atividade do MPF e permite a reconstrução da membrana nuclear. Assim, após a replicação do DNA, ocorre a divisão celular no embrião, originando o estádio de duas células (Pereira et al., 2009).

A oscilação do cálcio intracitoplasmático pode ser induzida pela exposição ao ionóforo de cálcio A23187 que promove a entrada de $\mathrm{Ca}^{+2}$ extracelular. A ionomicina é outro potente ionóforo do $\mathrm{Ca}^{+2}$, freqüentemente usada em protocolos de ativação em transferência nuclear. Essa substância mobiliza $\mathrm{Ca}^{+2}$ pela depleção de estoques intracelulares. A ativação induzida pelo etanol $7 \%$ induz a formação de $\mathrm{IP}_{3} \mathrm{e}$ promove um influxo de cálcio extracelular (Albeiro et al., 2001).

\section{Fatores que afetam o sucesso da scnt}

Para se atingir maior eficiência na SCNT é importante levar o núcleo da célula somática ao estado de totipotencia, desregularizando os genes que normalmente cumprem uma função predeterminada.
As mudanças que acontecem para reprogramar a célula são mudanças epigenéticas. Um dos mecanismos mais importantes na reprogramação é a metilação, que consiste em transferir grupos metil a algumas das citosinas (C) do DNA situadas adjacentes a uma guanina (G). Isso provoca uma mudança que impede a união da enzima RNA-polimerase evitando a transcrição (cópia) do gen alvo (Alberts et al., 2002).

A metilação é fundamental na regulação do silenciamento dos genes e pode provocar alterações na transcrição genética sem que se produza alteração na seqüência do DNA. A metilação favorece o silenciamento de genes e isso tem um papel importante no desenvolvimento normal dos órgãos e tecidos. Este é considerado um dos mecanismos responsáveis pela "plasticidade fenotípica", ou seja, a capacidade de mudar o fenótipo em resposta ao ambiente. Os produtos dos genes, as proteínas, também podem ser metiladas, regulando-se assim também sua função (Alberts et al., 2002).

\section{Herança epigenética}

A reprogramação epigenética é um fenômeno necessário para eliminar modificações epigenéticas adquiridas evitando assim sua transmissão para a descendência. Neste período os estudos de reprogramação gametogênica indicam que as mudanças epigenéticas podem desaparecer. Exemplo disso são os animais clonados obesos que tiveram descendência de animais não obesos, já que as modificações epigenéticas tinham sido controladas durante a reprogramação gametogênica (Tamashiro et al., 2000).

Os genes impressos (ou "imprinted"), observados depois da transferência dos embriões para a fêmea receptora, têm um papel importante na elevada mortalidade fetal. Alguns destes genes causadores das perdas embrionárias ou fetais são específicos da placenta, como o IGF2R (receptor do fator de crescimento semelhante a insulina II). A presença de alterações nestes genes foi demonstrada na placenta e tecidos fetais de camundongos (Yang et al., 2005).

Esta classe de genes denominados "imprinted" são expressos só em um dos dois alelos de um gene dependendo de sua procedência paterna ou materna. $\mathrm{Na}$ placenta dos camundongos clonados tem sido observada expressão anormalmente baixa destes genes, mas tal condição não foi localizada em outros tecidos. Tem-se detectado alterações no padrão de metilação do DNA em camundongos clonados nascidos com aparência física normal. Estas alterações na metilação do DNA produzido por SCNT nos teci- 
dos dos fetos durante o desenvolvimento embrionário permaneceram presentes nesses animais, mesmo nos adultos sadios (Coan et al., 2005; Inoue et al., 2002; Oghane et al., 2001).

Esta mudança no padrão de metilação não é exclusiva de SCNT, também tem sido detectado em embriões produzidos in vitro, produzindo problemas endócrinos que levam a um exagerado crescimento fetal (Hiendleder, 2004). No rato, por exemplo, foi comprovado que modificações causadas pelo ambiente podem desaparecer nas três gerações seguintes (Gluckman et al., 2007).

Em resumo a herança epigenética transgeneracional não é exclusiva de animais clonados; os animais reproduzidos de forma convencional também experimentam estes mecanismos (Gluckman et al., 2007).

\section{Erros na metilação}

Em estudos realizados com embriões pre-implantados de vacas clonadas observaram se regiões do genoma que não tinham sido demetiladas e mantinham os níveis de metilação da célula doadora do núcleo. Depois destas observações se realizaram modificações adicionando fatores do oócito e restabelecendo a demetilação observada (Kang et al., 2001).

Estes experimentos demonstraram que existem elementos do citoplasma que intervêm ativamente na reprogramação nuclear anulando a metilação do genoma paterno. Estes elementos do citoplasma (que não atuaram na demetilação dos primeiros ensaios) foram eliminados erroneamente pela técnica de enucleação do oócito. Por isso o aperfeiçoamento desta técnica é de vital importância para conseguir minimizar as causas da baixa taxa de sucesso da SCNT, e reduzir a inadequada desdiferenciação, que provoca padrões aberrantes na metilação global do DNA no zigoto, com consequências letais em determinados casos (Kang et al., 2001).

\section{Alterações na expressão gênica}

Estudos relacionados com a expressão de genes, em animais clonados, comparados com animais reproduzidos de maneira convencional ou por qualquer outra técnica de reprodução artificial, mostram que não existem diferenças relacionadas à expressão gênica ou que ainda tendo diferenças, o genoma pode tolerar certo grau de desregulação de seus genes sem provocar problemas ao animal (Boiani et al., 2005).

Por outro lado, estes estudos têm demonstrado que se produzem alterações na expressão dos genes em todas as técnicas de reprodução assistida, não só na SCNT, pelo que se deduz que as condições de cultivo são um fator importante para a correta expressão génica (BOIANI et al., 2005).

Humpherys (2001) analisou a expressão de mais de 10.000 genes da placenta e outros órgãos de camundongos clonados, e também da linhagem de células tronco que originou a célula doadora de núcleo para a construção do clone, tendo assim evidenciado que existem alterações na expressão dos genes, tanto nas células germinais, quanto nos embriões clonados; e também naqueles animais reproduzidos por outras técnicas de reprodução assistida (Humpherys et al., 2001).

Em camundongos obtidos por diversos métodos reprodutivos, incluindo a SCNT, estudou-se a expressão da proteína Oct4 pela sua importância no desenvolvimento embrionário já que falhas na expressão de Oct4 impedem o desenvolvimento a partir do estado de blastocisto, pelo que superar a primeira reprogramação nuclear não garante o desenvolvimento embrionário completo (Niwa et al., 2000).

Em todos os tipos de reprodução in vitro tem sido observadas alterações genéticas nos cromossomos na fase de preimplantação, principalmente naqueles embriões com malformações físicas. Entretanto também podem ser encontradas desordenes nos cromossomos, com um número não diplóide, em embriões fenotipicamente normais (Booth et al 2003; Hanada et al, 2005).

\section{Herança epigenetica transgeracional}

Não se tem dados suficientes para assegurar ou negar que as irregularidades na reprogramação nuclear possam ser transmitidas á descendência. Poderia se transmitir alguma irregularidade em um dos alelos dos genes, mas para que tal alteração possa ser detectada é preciso que ela seja fenotipicamente visível. É necessário analisar exaustivamente os descendentes dos animais clonados e ainda não tem transcorrido tempo suficiente para dispor de uma adequada quantidade de informação para tirar conclusões confiáveis.

Ortegon et al (2007) realizaram controles sobre descendentes (19 fêmeas e 11 machos) de um touro clonado e não encontrou anomalias ao nascimento.

Kasai (2007) reportou que não existiam anormalidades em uma bezerra de oito meses de idade nascida de animais clonados após analisar os resultados procedentes da análise clínica, bioquímicas, hematológicas, características do crescimento e análise de seus telômeros. 
Também Tamashiro (2000) pode comprovar como o caráter de obesidade de um camundongo clonado não foi transmitido para seus descendentes. As modificações epigenéticas podem ser transmitidas para sua progênie, mas há autores que opinam que essas alterações desaparecem apos três gerações, da mesma forma como nos animais reproduzidos de forma natural (Gluckman, et al., 2007).

\section{Modificação dos telômeros}

Os telômeros são estruturas cromossomais que podem influenciar no envelhecimento prematuro dos tecidos dos animais. Os telômeros são compostos por sequencias repetidas de DNA, que não codificam para nenhum gene em particular e se encontram nas extremidades dos cromossomos lineares. Uma de suas funções essenciais é proteger ao resto do cromossomo da degradação e da união dos extremos do DNA entre si por enzimas reparadoras. As células duplicam seu DNA previamente á divisão, mas não conseguem copiar a totalidade da seqüência dos telómeros e, como resultado, essas estruturas se tornam mais curtas em cada replicação (Hanada et al, 2005). O comprimento normal dos telômeros varia segundo a espécie e o cromossomo, o qual vai se encurtando segundo o tempo de vida do animal (Grider e Blackburn, 1989; Collins, 1996).

A telomerase é uma enzima que leva a cabo a elongação dos telômeros, permitindo a conservação do tamanho dessas estruturas após os ciclos de replicação, mas não está presente em todas as células. Quando uma linhagem celular não tem a telomerasa ativa, os telômeros vão se encurtando e a ativação ou desativação da telomerase influemcia no desenvolvimento e/ou envelhecimento dos tecidos de um organismo (Grider e Blackbrun, 1989).

A ovelha Dolly apresentava telômeros mais curtos em realação a outras ovelhas de mesma idade, indicando envelhecimento prematuro, o que fez pensar que a SCNT alterava os telômeros e provocava envelhecimento prematuro. Estudos posteriores em bovinos, suínos e caprinos têm mostrado que o comprimento dos telômeros foi igual nos animais clonados e reproduzidos de forma convencional; dessa forma, não pode se relacionar, exclusivamente, o comprimento dos telômeros com envelhecimento (Shiels et al, 1999; Kasai et al., 2007).

Estudos em animais clonados, fenotipicamente normais, mostraram que $21 \%$ deles apresentavam anormalidades no número de cromossomos com algumas células não diplóides. Essas anomalias não foram temporais (HANADA et al, 2005).

\section{O genoma mitocondrial}

O DNA mitocondrial ou genoma mitocondrial é o material genético contido nas mitocôndrias, as organelas citoplasmáticas que geram energia para a célula. O DNA mitocondrial é herdado apenas por via materna, já que as mitocôndrias espermáticas que penetram no ooplasma durante a fertilização são destruídas (Hiendler et al., 2005).

Na SCNT os embriões podem possuir mitocôndrias só procedentes do citoplasto (haloplasma) ou procedentes tanto da célula somática que doadora do núcleo quanto do citoplasto; ainda que a maioria dos animais estudados seja haloplasma, em raras ocasiões podem se encontrar um número elevado de mitocôndrias procedentes da célula somática (Burgstaller et al, 2007).

O número de mitocôndrias no oócito aumenta drasticamente durante a fertilização, pois são elementos essenciais no desenvolvimento embrionário. Não tem sido demonstrado ainda que os clones que apresentam DNA mitocondrial, do oócito e da célula somática, tenham maior probabilidade de apresentar alterações fenotípicas ou até perda embrionária. Mas algumas doenças metabólicas em animais clonados adultos poderiam ser decorrentes da presença de DNA mitocondrial da célula somática (Spikings et al, 2007, Smith et al., 2005; Bowles et al., 2007).

\section{Referencias}

Akagi S, Adachi N, Matsukawa K, Kubo M, Takahashi S. Developmental potential of bovine nuclear transfer embryos and postnatal survival rate of cloned calves produced by two different timings of fusion and activation. Molecular Reproduction and Development, 2003; 66: 264- 272.

Albeiro R, Zakhartchenko V, Motlik J, Wolf E. Mammalian oocyte activation: lessons from the sperm and implications for nuclear transfer. International journal of developmental biology, 2001; 45:797- 809.

Alberts B, Johnson A, Lewis J, Raff M, Roberts K, Walter P. Molecular Biology of the Cell, Garland Science Nueva York, 2002.

Baguisi A, Behboodi E, Melican D, Pollock J, Destrempes M, Cammuso C, et al. Production of goats by somatic cell nuclear transfer. Nature Biotechnology, 1999; 17: 456- 461.

Barañao L. Clonación animal: Mitos y realidades. Em: Sitio argentino de producción animal. http: //www. produccionanimal.com. ar/genetica_seleccion_ cruzamientos/genética (acceso em: setembro 2 de 2012 as 10:40 am)

Boiani M, Eckardt S, Scholer H, Mclaughlin K. Oct4 distribution and level in mouse clones: consequences for pluripotency, Genes and Development, 2002:16(10):12091219.

Boiani M, Gentile L, Gambles V, Cavaleri F, Redi C, Scholer 
$\mathrm{H}$. Variable 'reprogramming' of the pluripotent stem cell marker Oct4 in mouse clones: distinct developmental potentials in different culture environments", Stem Cells (Dayton, Ohio), 2005; 23(8):1089- 1104.

Booth PJ, Viuff D, Tan S, Holm P, Greve T, Callesen H. Numerical chromosome errors in day 7 somatic nuclear transfer bovine blastocysts", Biology of Reproduction, 2003; 68(3):922- 928.

Bowles EJ, Campbell KH, ST JOHN JC. "Nuclear transfer: preservation of a nuclear genome at the expense of its associated mtDNA genome(s)", Current Topics in Developmental Biology, 2007; 77: 251-290.

Bressan F, Miranda M, De Bem T, et al. Produção de animais transgênicos por transferência nuclear como modelo de estudo biológico. Revista brasileira de reprodução animal, 2008;32:240- 250.

Briggs R, King T. "Transplantation of living nuclei from blastula cells into enucleated frogs' eggs", Proceedings of the National Academy of sciences United States of America, 1952; 38(5): 455- 463.

Bromhall J. "Nuclear transplantation in the rabbit egg", Nature, $1975 ; .258: 719-722$.

Burgstaller J, Schinogl P, Dinnyes A, Müller M, Steinborn R. Mitochondrial DNA heteroplasmy in ovine fetuses and sheep cloned by somatic cell nuclear transfer. BMC Developmental Biology, 2007;7:141.

Campbell K. "Sheep cloned by nuclear transfer from cultured cell line", Nature, 1996; 380:64- 66.

Campbell K, Loi P, Otaegui P, Wilmut I. Cell cycle coordination in embryo cloning by nuclear transfer. Rev Reprod, 1996; : : 40-46.

Campbell K, Alberio R, Choi I, Fisher P, Kelly R, Lee J, Maalouf W. Cloning: eight years after Dolly. Reproduction in Domestic Animals, 2005; 40: 256-268.

Campbell K, Fisher P, Chen W, Choi I, Kelly R, Lee J, Xhu J. Somatic cell nuclear transfer: Past, present and future perspectives. Theriogenology, 2007; 68: S214- S231.

Chesné P. Métodos de clonagem em caprinos e ovinos. In: Freitas VJF (Ed). Produção de embriões por transferência nuclear (clonagem). Fortaleza: Multicor, 2006; 21-29.

Coan PM, Burton GJ, Ferguson-Smith AC."Imprinted genes in the placenta", Placenta, 2005; 26(Suppl A): S10-20.

Collins K. Structure and function of telomerase. Current Opin Cell Biol, 1996;8:374- 80.

De Miguel Berian I. La clonación diez años después, Comares, Granada, 2008.

Frist N. "Nuclear transplantation in the bovine embryos: Assessment of donor nuclei and recipient oocyte", Biology of Reproduction, 1987; 37(4):859-866.

Gindoff P. Clonación por separación embrionaria, En las fronteras de la vida: ciencia y ética de la clonación, Fundación Ciencias de la Salud, Ediciones Doce Calles, Madrid, 1998; 52- 61.

Gluckman P, Hanson MA, Beedle A. Non-genomic transgenerational inheritance of disease risk. Bioessays: news and reviews in molecuar, cellular and developmental biology, 2007; 29(2):145- 154.

Greider C, Blackburn E. A telomeric sequence in the RNA of Tetrahymena telomerase required for telomere repeat synthesis. Nature, 1989;7:337-331.
Gurdon J. "The developmental capacity of nuclei taken from intestinal epithelium cells of feeding tadpoles", Journal of embryology experimental morphology, 1962;.10: 622- 640.

Gurdon J. "The transplantation of nuclei between two species of Xenopus", Developmental Biology, 1965; 5: 68-83.

Heyman Y, Chavatte-Palmer P, Lebourhis D, Camous S, Vignon $X$, Renard J. Frequency of ocurrence of late gestation losses from cattle cloned embryos. Biology of reproduction, 2002; 66: 6-13.

Heyman Y. Nuclear transfer: a new tool for reproductive biotechnology in cattle. Reproduction Nutrition Development, 2005; 45: 353-361.

Hiendleder S, Mund C, Reichenbach HD, Wenigerkind H, Brem G, Zakhartchenko V, Lyko F, Wolf E. "Tissue-specific elevated genomic cytosine methylation levels are associated with an overgrowth phenotype of bovine fetuses derived by in vitro techniques", Biology of Reproduction, 2004; 71(1):217- 223.

Hanada H, Takeda K, Tagami T, Nirasawa K, Akagi S, Adachi $\mathrm{N}$, Takahashi S, Izaike $\mathrm{Y}$, Iwamoto $\mathrm{M}$, Fuchimoto D, Miyashita N, Kubo M, Onishi A, King W. Chromosomal instability in the cattle clones derived by somatic cell nuclear-transfer. Molecular Reproduction and Developmental, 2005;71(1):36-44.

Hiendleder S, Zakhartchenko V, Wolf E. Mitochondria and the success of somatic cell nuclear transfer cloning: from nuclear-mitochondrial interactions to mitochondrial complementation and mitochondrial DNA recombination. Reproduction, Fertility and Developmental, $2005 ; 17(1-2)$ : 69-83.

Humpherys D, Eggan K, Akutsu H, Hochedlinger K, Rideout WM, Biniszkiewicz D, Yanagimachi R, Jaenisch R. Epigenetic instability in ES cells and cloned mice. Science, 2001; 293:95-97.

Hyttel P, Laurincik J, Overstrom E. Nucleolar protein allocation and ultrastructure in bovine embryos produced by nuclear transfer from embryonic cells. Cloning, 2001;3:69-82.

Ibáñez E, Albertini D, Overstrom E. Demecolcina-induced oocyte enucleation for somatic cell cloning coordination between cell-stage egress, kinetics of cortical cytoskeletal interactions, and second polar body extrusion. Biology of Reproduction, 2003; 68:1249-1258.

Illmense K, Hoppe P. "Nuclear transplantation in mus musculus: Developmental potential of nuclei from preimplantation embryos", Cellular, 1981;23(1):9-18.

Inoue K, Kohda T, Lee J, Ogonuki N, Mochida K, Noguchi Y, Tanemura K, Kaneko-Ishino T, Ishino F, Ogura A. "Faithful expression of imprinted genes in cloned mice", Science, 2002; 295(5553): 297.

Jang G, Park G, Bhuiyan M, Lee B, Kang S, Hwang W. Preimplantational embryo development and incidence of blastomere apoptosis in bovine somatic cell nuclear transfer embryos reconstructed with long term cultured donor cells. Theriogenology, 2004; 62: 512-521.

Kang YK, Koo DB, Park JS, Choi YH, Chung AS, Lee K, Han Y. Aberrant methylation of donor genome in cloned bovine embryos. Nature Genetics, 2001; 28(2):173-177.

Kato Y, Tani T, Tsunoda Y. Cloning of calves from various somatic cell types of male and female adult, newborn and fetal cows. Journal of Reproduction and Fertility, 2000;120:231-237. 
Kasai K, Sano F, Miyashita N, Watanabe S, Nagai T. Comparison of the growth performances of offspring produced by a pair of cloned cattle and their nuclear donor animals. Journal of Reproduction Developmental, 2007;53(1):135-142.

Kurome M, Fujimura T, Murakami H, Takahagi $\mathrm{Y}$, Wako N, Ochiai T, Miyazaki K, Nagashima H. Comparison of electro-fusion and intracytoplasmic nuclear injection methods in pig cloning. Cloning Stem Cells, 2003; 5:367-378.

Lee S, Kumar B, Kim J, Ock S, Jeon B, Balasubramanian S, Choe S, Rho G. Cellular composition and viability of cloned bovine embryos using exogene-transfected somatic cells. Reproduction in Domestic Animals, 2007; 42: 44-52.

Li G, White K, Bunch T. Review of enucleation methods and procedures used in animal cloning: state of the art. Cloning Stem Cells, 2004; 6:5-13.

McGrath J, Solter D. "Inability of mouse blastomere nuclei transferred to enucleated zygotes to support development in Vitro", Science, 1984;226:1317-1318.

Martínez M, Mori T, Nagano M, Katagiri S, Takahashi Y. Effect of fusion/activation protocol on in vitro development of porcine nuclear transfer embryos constructed with foreign genetransfected fetal fibroblasts. Journal of Veterinary Medical Science, 2003;65:989-994.

Martinez M, Gatica R, Correa J, Eyestone W. Gestaciones producidas com embriones bovinos clonados producidos por transferência nuclear. Archivos de medicina veterinária,2007;39(1):59-62.

Martins C, Saueressig M, Bezerra S, et al. Isolamento, cultivo e criopreservação de fibroblastos bovinos recuperados de pele de orelha resfriada a 3 graus Celsius por longos períodos. Em: II Simpósio internacional savanas tropicais, Brasília, DF. 12 a 17 de outubro de 2008.

Miyoshi K, Rzucidlo S, Pratt S, Stice S. Improvements in cloning efficiencies may be possible by increasing uniformity in recipient oocytes and donor cells. Biology of reproduction, 2003;68:1079-1086.

Niwa H, Miyazaki J, Smith A. Quantitative expression of Oct-3/4 defines differentiation, dedifferentiation or self-renewal of ES cells. Nature Genetics, 2000; 24(4):372-376

Ohgane J, Wakayama T, Kogo Y, Senda S, Hattori N, Tanaka S, Yanagimachi R, Shiota K. "DNA methylation variation in cloned mice", Genesis, 2001;30(2):45-50.

Ortegon H, Betts D, Lin L, Coppola G, Perrault S, Blondin P, King W. "Genomic stability and physiological assessments of live offspring sired by a bull clone, Starbuck II", Theriogenology, 2007; 67(1):116-126.

Pereira A, Freitas V. Clonagem em ruminantes: progressos e perspectivas atuais. Revista Brasileira de reprodução animal, 2009;33(3):118-128.

Prathers R. Nuclear transplantation in the bovine embryo: assessment of donor nuclei and recipient oocyte, Biology of Reproduction,1987;37(4):859- 866.

Recuerda Vega C. Seguridad alimentaria y alimentos procedentes de animales clonados por transferencia nuclear de células somáticas: Aspectos científicos, éticos y jurídicos. Tesis Doctoral, Universidad Complutense de Madrid (ISBN: 978-84-695-1010-0), facultad de Veterinaria. 2011.
Sá R, Sousa M, Cremades N, Alves C, Pinho M, Silva J, Barros A. Haploidização. Revista Internacional de Andrología, 2006; 4(1): 9-24.

Shiels PG, Kind AJ, Campbell KH, Wilmut I, Waddington D, Colman A, Schnieke A. Analysis of telomere length in Dolly, a sheep erived by nuclear transfer. Cloning, 1999;1(2):119-125

Sims M, First N. Production of calves by transfer of nuclei from cultured inner mass cells, Proceedings of the National Academy of Sciences, 1994;91(13):6143-6147.

Smith LC, Thundathil J, Filion F. "Role of the mitochondrial genome in preimplantation development and assisted reproductive technologies", reproduction, Fertility and Developmental, 2005; 17(1-2):15-22.

Spikings E, Alderson J, John J. Regulated mitochondrial DNA replication during oocyte maturation is essential for successful porcine embryonic development. Biology of Reproduction, 2007; 76(2):327-335.

Tamada H, Kikyo N. Nuclear reprogramming in mammalian somatic cell nuclear cloning. Cytogenet Genome Res, 2004;105:285-291.

Tamashiro KL, Wakayama T, Blanchard RJ, Blanchard DC, Yanagimachi R., "Postnatal growth and behavioral development of mice cloned from adult cumulus cells", Biology of Reproduction, 2000;63(1):328-334.

Tian X, Kubota C, Enright B, Yang X. Cloning animals by somatic cell nuclear transfer: biological factors. Reprod Biol Endocrinol, 2003; 13:1-98.

Velilla E, López-Béjar M, Rodríguez-González E, Vidal F, Paramio M. Effect of Hoechst 33342 staining on developmental competence of prepubertal goat oocytes. Zygote, 2002;10: 201-208.

Wakayama T, Rodríguez I, Perry ACF, Yanagimachi R, Mombaerts P. "Mice cloned from embryonic stem cells", Proceedings of the National Academy of Sciences, 1999; 96(26):14984-14989.

Wells D. Animal cloning: problems and prospects. Rev Sci Tech. 2005; 24: 251-264.

Willadsen S. "Nuclear transplantation in sheep embryos", Nature, 1986;320:63- 65

Wilmut I, Schnieke A, Mcwhir J, Kind A, Campbell KH. "Viable offspring from fetal and adult mammalian cells", Nature, 1997; 385: 810- 813.

Wilmut I. "Are there any normal cloned mammals?" Nature Medicine, 2002; 8(3):215-216.

Yamanaka S. Induction of plupotent stem sell from mose fibroblast by four transcription factors. Cell Prolif, 2008;41(Suplemento 1):51- 56.

Yang L, Chavatte-Palmer P, Kubota C, O’Neill M, Hoagland $\mathrm{T}$, et al. Expression of imprinted genes is aberrant in deceased newborn cloned calves and relatively normal in surviving adult clones. Molecular Reproduction Development, 2005; 71(4): 431-438.

Zhou H, Liu C, Wang W. Heterospecific nuclear-transferred embryos derived from equine fibroblast cells and enucleated bovine oocytes. Reproduction in Domestic Animals, 2007;42:243-247.

Zou X, Chen Y, Wang Y, Luo J, Zhan Q, Zhang X, Yang Y, Ju H, Shen Y, Lao W, Xu S, Du M. Production of cloned goats from enucleated oocytes injected with cumulus cell nuclei or fused with cumulus cells. Cloning, 2001;3: 31-37. 